\title{
DIAGNÓSTICO POR IMAGEM DOS TUMORES DA NASOFARINGE*
}

\author{
Ilka Yamashiro ${ }^{1}$, Ricardo Pires de Souza ${ }^{2}$
}

Resumo A nasofaringe é a parte mais superior das vias aéreas superiores. Seu limite superior é a base do osso esfenóide e occipital, situa-se anteriormente às duas primeiras vértebras cervicais e à frente do clivo. Seus limites laterais são formados pelas margens do músculo constritor superior da faringe e pela fáscia faringobasilar, recessos faríngeos, toro tubário e tuba auditiva. 0 limite inferior é um plano horizontal que passa pelo palato duro e pelo músculo palatofaríngeo. Anteriormente, comunica-se com a cavidade nasal via coana posterior. Mede cerca de 2,0 cm de diâmetro ântero-posterior e cerca de 4,0 cm de extensão crânio-caudal. 0 carcinoma de células escamosas compreende aproximadamente $70 \%$ a $98 \%$ de todas as neoplasias malignas da nasofaringe em adultos. Este tipo de tumor apresenta alta incidência na população asiática, sendo mais comum entre os homens e o terceiro mais comum entre as mulheres. A manifestação clínica do carcinoma da nasofaringe depende do tamanho da lesão e da sua localização, sendo que as lesões de pequenas dimensões são geralmente assintomáticas. A tomografia computadorizada e a ressonância magnética desempenham papel essencial e complementar no estadiamento e no tratamento dos pacientes portadores de câncer da nasofaringe.

Unitermos: Tomografia computadorizada; Nasofaringe; Tumor; Carcinoma.

Abstract Imaging diagnosis of nasopharyngeal tumors.

The nasopharynx is located in the upper aerodigestive tract. Its roof is formed by the basisphenoid, basiocciput and the anterior aspect of the first two cervical vertebrae, in front of the clivus. The lateral walls are formed by the margins of the superior constrictor muscle and the pharyngobasilar fascia, pharyngeal recess, torus tubarius and pharyngeal opening of auditory tube. The inferior margin of the nasopharynx is a horizontal plane passing through the hard palate and palatopharyngeal muscle. Anteriorly, it is in direct continuity with the nasal cavity through the posterior choanae. It is approximately $2.0 \mathrm{~cm}$ in anteroposterior diameter and about $4.0 \mathrm{~cm}$ in craniocaudal extent. Squamous cell carcinoma accounts for about $70 \%$ to $98 \%$ of nasopharyngeal malignant lesions found in adults. This tumor presents a high incidence in Asians, most frequently in men, and is the third most frequent cancer in women. The clinical presentation of this disease depends on the size and site of the lesion, with small-sized lesions being asymptomatic. Computed tomography and magnetic resonance imaging play essential and complementary roles in the staging and treatment of patients with nasopharyngeal cancer.

Keywords: Computed tomography; Nasopharynx; Tumor; Carcinoma.

\section{SUBSTRATO ANATÔMICO}

A nasofaringe é a parte mais superior das vias aéreas superiores e compõe o segmento superior da faringe. Seus principais reparos anatômicos são o recesso faríngeo lateral, o toro tubário e a tuba auditiva.

A nasofaringe situa-se abaixo da base do crânio, anteriormente ao clivo, continuase anteriormente com a cavidade nasal e inferiormente com a orofaringe, da qual é

* Trabalho realizado no Serviço de Diagnóstico por Imagem do Serviço de Radiologia do Hospital Heliópolis, São Paulo, SP.

1. Médica Estagiária do Serviço de Diagnóstico por Imagem do Serviço de Radiologia do Hospital Heliópolis, Mestranda em Ciências da Saúde do Hospital Heliópolis.

2. Coordenador da Residência Médica em Diagnóstico por Imagem do Serviço de Radiologia do Hospital Heliópolis.

Endereço para correspondência: Dra. Ilka Yamashiro. Rua Afonso Celso, 1637, ap. 33, Chácara Inglesa. São Paulo, SP, 04119-062. E-mail: ilkay@terra.com.br

Recebido para publicação em 28/10/2004. Aceito, após revisão, em 17/3/2005. separada por um plano horizontal que passa pelo palato duro e o músculo palatofaríngeo. Lateralmente, é limitada pelas margens do músculo constritor superior, pela fáscia faringobasilar e pelo espaço parafaríngeo $^{(\mathbf{1})}$. Sua parede é composta por três camadas: revestimento mucoso, camada muscular e armação fibrosa denominada fáscia faringobasilar.

Mede cerca de 2,0 cm de diâmetro ântero-posterior e cerca de $4,0 \mathrm{~cm}$ de extensão crânio-caudal ${ }^{(2)}$.

A lâmina média da fáscia cervical profunda ou fáscia bucofaríngea é uma condensação de tecido celular que circunda a porção lateral e posterior da nasofaringe, dando-lhe delimitação fascial e intermediando suas relações com estruturas vizinhas. É delicada, tênue, não representando barreira significativa à disseminação neoplásica ou infecciosa da nasofaringe para espaços adjacentes $^{(\mathbf{3 , 4})}$. Recobre lateralmente os músculos da faringe, tendo inserção superior na base do crânio no tubérculo faríngeo, com o músculo constritor da faringe, com a fáscia faringobasilar e na margem posterior da lâmina medial do processo pterigóideo.

A protrusão de estruturas e a composição da parede faríngea dão forma ao relevo mucoso da nasofaringe, determinando pontos de reparo anatômicos que são utilizados na avaliação clínica e na interpretação dos cortes seccionais de tomografia computadorizada (TC) e ressonância magnética (RM). São eles: a) o toro tubário, a mais proeminente dessas estruturas, correspondendo à protrusão de parte da cartilagem da tuba auditiva. É visualizado como protuberância projetando-se para dentro da cavidade nasofaríngea em sua parede lateral, tanto na TC quanto na RM; b) o óstio 
da tuba auditiva, localizado em situação imediatamente ântero-inferior ao toro tubário $^{(5)}$. Nos cortes axiais de TC e RM aparece como discreta reentrância na parede lateral da nasofaringe; c) a prega salpingofaríngea, protrusão da mucosa determinada pelo trajeto submucoso do músculo salpingofaríngeo, formando o limite anterior do recesso faríngeo lateral; d) o recesso faríngeo lateral, situado posteriormente e estendendo-se superiormente em relação à prega salpingofaríngea e ao toro tubário (Figuras 1 e 2). É o sítio mais comum de origem do carcinoma de células escamosas da nasofaringe ${ }^{(6)}$. Sua origem se dá pela discreta herniação mucosa por uma zona da parede faríngea que não dispõe de fibras musculares (seio de Morgagni) O grau de distensibilidade deste recesso é altamente variável.

Ele tende a ser simétrico, embora discretas assimetrias não sejam incomuns na RM e na $\mathrm{TC}^{(7)}$. Em jovens tem menor amplitude devido à maior presença de tecido linfóide retrofaríngeo $^{(8)}$

A nasofaringe é constituída por:

a) Uma camada muscular, formada pelos músculos constritores da faringe superior, média e inferior, levantadores da faringe (palatofaríngeo, estilofaríngeo e salpingofaríngeo), palatoglosso, levantador e tensor do véu palatino e o músculo palatofaríngeo;

b) uma armação fibrosa ou fáscia faringobasilar, situada entre a túnica muscular e a mucosa, estendendo-se sem interrupção da extremidade superior à inferior da faringe, não existindo na parte anterior, exceto na aderência com a laringe, onde é circular $^{(\mathbf{1})}$. Cranialmente, onde sua superfície externa não é recoberta pela camada muscular (entre a base do crânio e a porção ínfero-lateral da cartilagem da tuba auditiva), existe um entalhe lateral denominado seio de Morgagni. É por este espaço que a tuba auditiva e o músculo levantador do véu palatino penetram para atingir a porção interna da nasofaringe. O seio de Morgagni, por sua característica anatômica, é importante via de disseminação do carcinoma da nasofaringe para os espaços vizinhos, como o parafaríngeo;

c) um revestimento mucoso ou túnica interna, que reveste a face interna da fáscia faringobasilar e tem continuidade com o revestimento mucoso da cavidade nasal e orofaringe. É constituído por epitélio e por córion rico em glândulas mucíparas e em folículos linfóides. Seu epitélio é do tipo cilíndrico ciliado pseudo-estratificado ${ }^{(9)}$. No córion temos abundância de te- cido linfóide, com formações que vão compor parte do anel linfático da faringe, que pode ser sítio de desenvolvimento de linfoma não-Hodgkin, que é a segunda neoplasia maligna mais comum da nasofaringe $^{(2,10)}$. Glândulas salivares menores estão presentes na submucosa em torno das tubas auditivas e podem ser foco de lesões benignas ou malignas da nasofaringe.

O conhecimento da ocorrência de variantes anatômicas é importante para que não se confunda alterações da normalidade com doença.

A assimetria dos pontos de reparo da mucosa é variação de ocorrência comum destacando-se a assimetria do recesso faríngeo. A diminuição da profundidade ou mesmo colabamento deste recesso faríngeo como aspecto normal deve ser diferenciada de doença. A análise dos planos profundos adjacentes, havendo integridade e simetria destes, sugere normalidade (Figura 3). Também a obtenção de imagens na TC durante manobra de Valsalva modificada ou ampla abertura da boca poderá ser útil. A manobra de Valsalva modificada leva à máxima distensão do óstio da tuba auditiva e do recesso faríngeo. A ampla abertura da boca distende o recesso faríngeo e aumenta a profundidade do óstio tubário ${ }^{(7)}$.

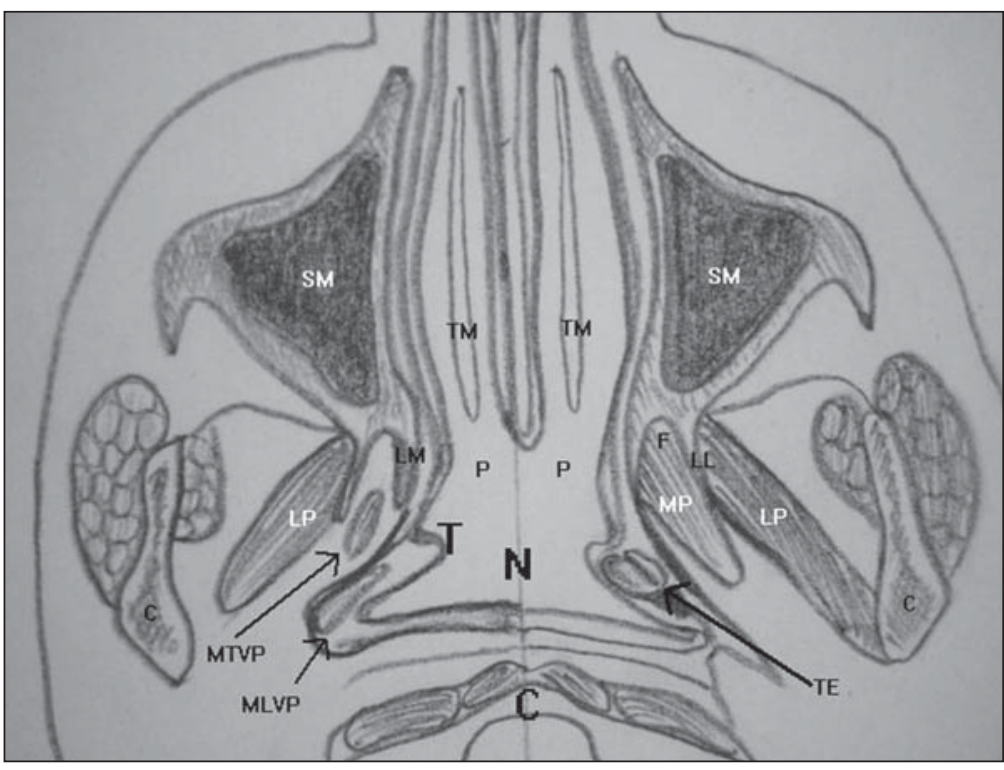

Figura 1. Desenho esquemático da visão axial, em planos ligeiramente diferentes: SM, seio maxilar; TM, turbina média; P, coana posterior; N, nasofaringe; LM, lâmina pterigóidea medial; F, fossa pterigóidea; LL, lâmina pterigóidea lateral; LP, músculo pterigóideo lateral; MP, músculo pterigóideo medial; TE, tuba auditiva (tuba de Eustáquio); T, toro tubário; FR, recesso faríngeo (fosseta de Rosenmuller); CL, clivo; C, côndilo mandibular; MTVP, músculo tensor do véu palatino; MLVP, músculo levantador do véu palatino.

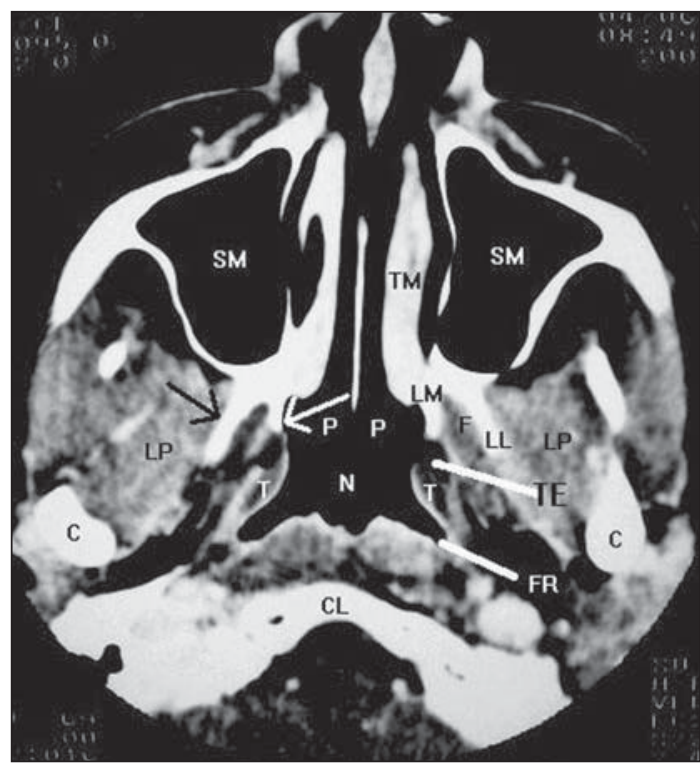

Figura 2. TC axial pós-contraste: anatomia normal. SM, seio maxilar; TM, turbina média; $\mathrm{P}$, coana posterior; $\mathrm{N}$, nasofaringe; LM, lâmina pterigóidea medial (seta branca); F, fossa pterigóidea; LL, lâmina pterigóidea lateral (seta preta); LP, músculo pterigóideo lateral; TE, tuba auditiva (tuba de Eustáquio); T, toro tubário; FR, recesso faríngeo (fosseta de Rosenmuller); CL, clivo; C, côndilo mandibular. 
O tecido linfóide nasofaríngeo pode, às vezes, assemelhar-se a processo tumoral. Sabendo-se que seu limite normal é a mucosa e a submucosa, a extensão para planos profundos deve ser considerada como evidência de lesão maligna ou processo inflamatório agressivo ${ }^{(11,12)}$.

Com o avanço da idade há diminuição do volume do tecido linfóide, dos músculos levantador e tensor do véu palatino, músculos constritores e aumento de tecido gorduroso. Essas modificações são conhecidas como atrofia nasofaríngea. Na avaliação radiológica observamos aumento do tamanho do recesso faríngeo lateral, com maior proeminência do toro tubário e do óstio tubário.

Deve-se ressaltar que se não houver total esclarecimento quanto à assimetria nos cortes axiais, torna-se mandatória a realização de cortes coronais, principalmente em alterações da extremidade superior do recesso lateral $^{(\mathbf{1 3 )}}$ (Figura 4).

\section{ESTADIAMENTO LOCAL DOS CARCINOMAS DA NASOFARINGE}

O carcinoma de células escamosas compreende aproximadamente $70 \%$ a $98 \%$ de todas as neoplasias malignas da nasofaringe. Os linfomas compõem cerca de $20 \%$ dos casos e os restantes $10 \%$ são causados por uma variedade de lesões, incluindo os adenocarcinomas, o carcinoma adenóide cístico, os rabdomiossarcomas, etc. O carcinoma de células escamosas da nasofaringe é um câncer relativamente raro, compreendendo $0,25 \%$ das neoplasias malignas na América do Norte, porém apresenta alta incidência entre os asiáticos, principalmente do sudeste asiático, chegando a compreender $18 \%$ de todos os cânceres na China $^{(2)}$. Tende a afetar grupo etário mais jovem que outras lesões do trato aerodigestivo superior, sendo mais comum em homens do que em mulheres ${ }^{(14)}$.

Os fatores de risco para o desenvolvimento do carcinoma da nasofaringe incluem os mesmos da orofaringe, como o consumo de nitrosaminas (presentes em condimentos alimentares) e hidrocarbonetos policíclicos, o uso crônico de álcool e tabaco, condições precárias de vida, infecções nasossinusais de repetição, e há forte associação com a infecção pelo vírus Epstein-Barr, principalmente em pacientes do sudeste asiático, onde a população afetada geralmente é mais jovem quando comparada à população caucasiana ${ }^{(2)}$.

A classificação da Organização Mundial da Saúde, recentemente, atualizou a classificação histológica dos carcinomas da nasofaringe, dividindo-os em dois maiores subtipos: 1 - o carcinoma de células esca- mosas; 2 - o carcinoma de células nãoqueratinizadas.

O subtipo carcinoma de células nãoqueratinizadas é, ainda, subdividido em subtipo I - diferenciado (2a) e II - indiferenciado (2b). O termo linfoepitelioma também é usado para designar estes dois subtipos de tumor. Essas novas nomenclaturas $2 \mathrm{a}$ e $2 \mathrm{~b}$ correspondem aos antigos tipos 2 e 3 da antiga classificação, respectivamente $^{(2)}$. Este último, o carcinoma de células não-queratinizadas subtipo indiferenciado, parece estar mais relacionados à infecção pelo vírus Epstein-Barr, promovendo de maneira ainda incerta o desenvolvimento do câncer em pacientes mais jovens ${ }^{(15-17)}$. Ainda, a presença do genoma viral (vírus Epstein-Barr) em linfonodos metastáticos pode sugerir um carcinoma da nasofaringe como sítio primário ${ }^{(\mathbf{1 8})}$.

O sítio de origem é variado. Os locais mais comuns são as paredes laterais da nasofaringe, mais freqüentemente o recesso faríngeo lateral e muitas vezes o toro tubário está envolvido ${ }^{(\mathbf{1 4 , 1 9 , 2 0})}$ (Figuras 5A e 5B).

A manifestação clínica do carcinoma de nasofaringe depende do tamanho, da localização e da rota de disseminação provocada por esses tumores. Geralmente, pequenas lesões são assintomáticas. Porém, otite média serosa, cefaléia, obstrução nasal, epistaxe, "dor de garganta", trismo e

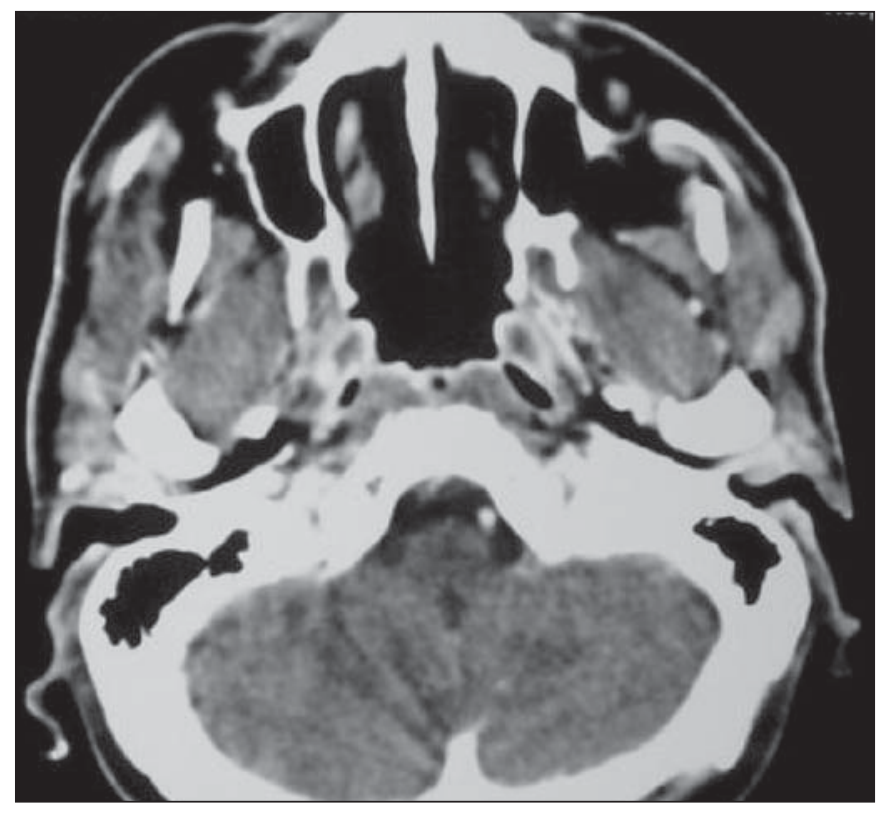

Figura 3. TC axial pós-contraste: assimetria normal do recesso faríngeo. Notar que o recesso à direita é menos evidente que à esquerda, porém os tecidos adjacentes não apresentam nenhuma alteração.

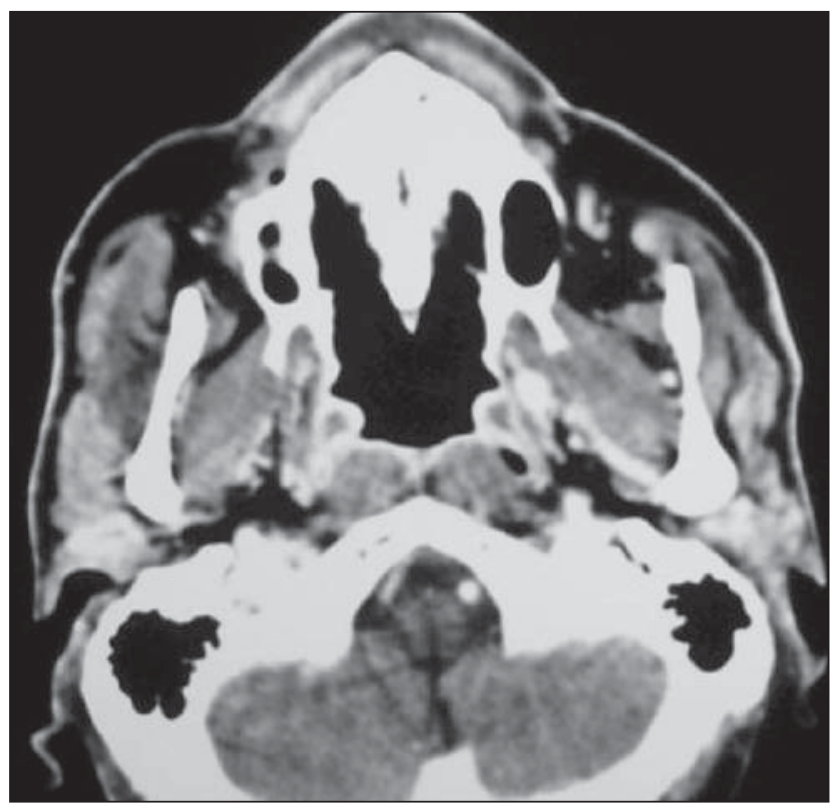

Figura 4. TC axial pós-contraste: assimetria normal do recesso faríngeo. Notar que o recesso à direita apresenta-se obliterado, sem anormalidades dos tecidos adjacentes. 

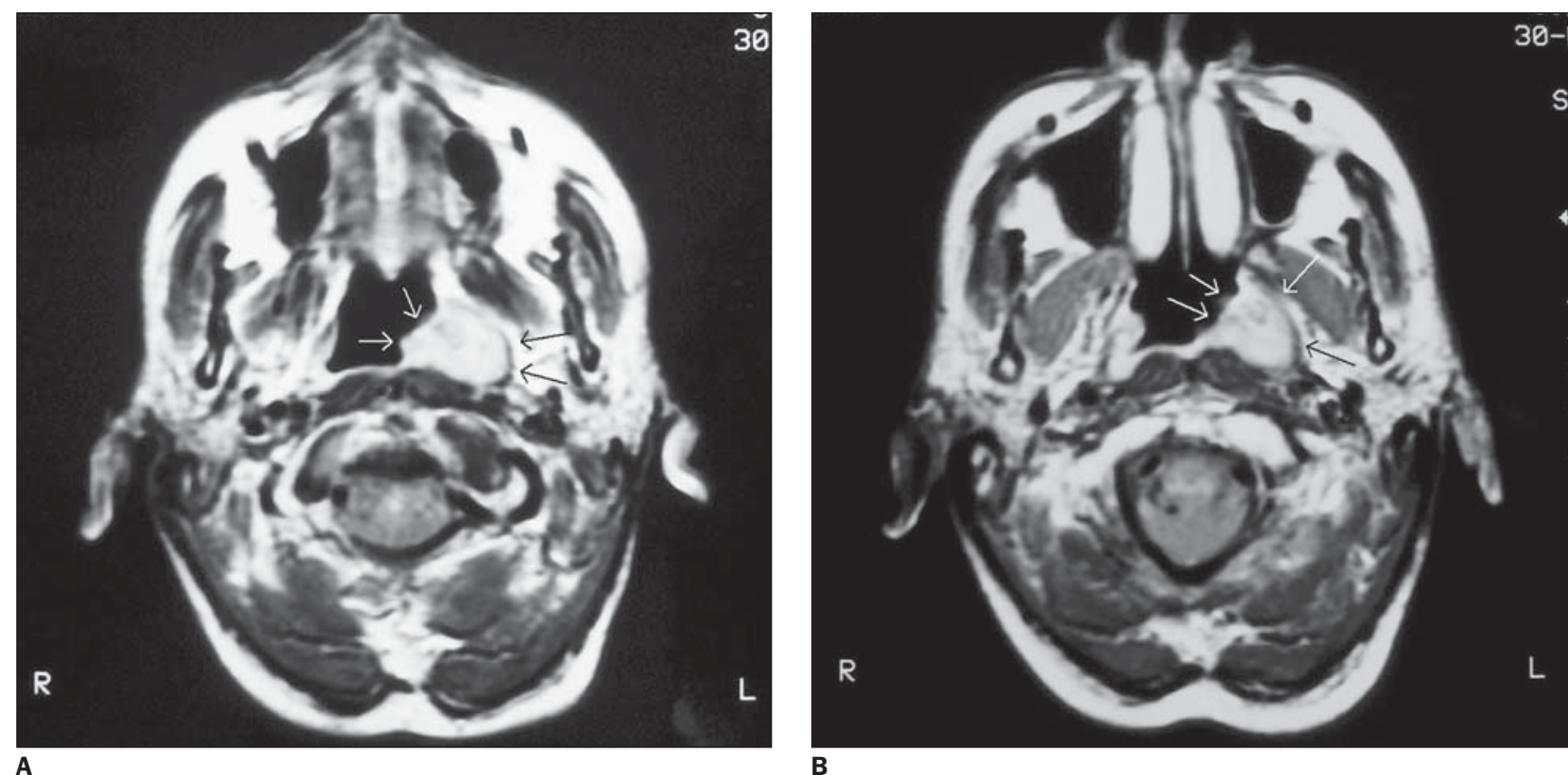

Figura 5(A,B). RM axial T2(TR 2.500/TE 25). Assimetria com obliteração do recesso faríngeo à esquerda por presença de lesão bem delimitada, que apresenta hipersinal nesta seqüência (setas).

proptose podem estar presentes, dependendo do grau de acometimento das estruturas vizinhas e do tamanho da lesão ${ }^{(2)}$. Outros sintomas menos comuns podem estar presentes, como hemotímpano, massa periauricular, sensação de "ouvido tampado", barotrauma, pólipo no interior da orelha interna e perda auditiva neurossensorial súbita ${ }^{(21)}$.

Vias anatômicas específicas pelas quais o tumor se estende para a base do crânio ou regiões intracranianas são inferidas por imagens de TC e RM, assim como a disseminação metastática linfonodal ou a distância.

O carcinoma da nasofaringe é um dos poucos tumores da cabeça e pescoço que não apresenta relação entre o tamanho tumoral e a presença de metástases linfonodais, e isto se deve ao extenso plexo de drenagem linfática presente na região. Cerca de $90 \%$ dos casos apresentam-se com metástases linfonodais no momento do diagnóstico e, ainda, 50\% deles já apresentam doença bilateral $^{(\mathbf{1 7})}$.

O sítio primário de drenagem é para os linfonodos retrofaríngeos, mas como podem apresentar-se obliterados na idade adulta por processos inflamatórios/infecciosos ocorridos na infância, estes linfonodos podem não se apresentar acometidos. Outros sítios de drenagem preferencial são para os níveis II, III e ocasionalmente $\mathrm{V}^{(2)}$.
Metástases a distância podem acometer os pulmões, o esqueleto, o fígado e ocasionalmente o plexo coróide ${ }^{(17)}$.

Em geral, os carcinomas de nasofaringe se disseminam através da mucosa e submucosa ao longo dos grupamentos musculares e em suas origens e inserções, junto aos planos gordurosos que circundam os músculos, ao longo dos feixes vásculo-nervosos e pelos forames criados para passagem normal dessas estruturas. Algumas estruturas são mais resistentes à invasão tumoral, como a porção cartilaginosa da tuba auditiva e a fáscia faringobasilar ${ }^{(\mathbf{2 , 1 9}, \mathbf{2 2}, 23)}$.

A disseminação perineural é a forma mais insidiosa de disseminação tumoral e é de fundamental importância para o planejamento terapêutico e prognóstico. $\mathrm{O}$ nervo do canal pterigóideo representa a principal rota de disseminação perineural do carcinoma de nasofaringe. Deve-se suspeitar de invasão perineural quando há alargamento ou realce anormal do nervo com obliteração dos planos gordurosos ${ }^{(24)}$.

$\mathrm{O}$ carcinoma da nasofaringe origina-se, comumente, na região do recesso faríngeo lateral. $\mathrm{Na} \mathrm{TC}$, usualmente nota-se assimetria, borramento ou obliteração desse recesso, que pode estar associado a aumento do músculo levantador do véu palatino ${ }^{(6,19,25)}$.

Quando o tumor ultrapassa a fáscia faringobasilar, invade o espaço parafaríngeo, ocorrendo em $65 \%$ dos casos de carcinoma de nasofaringe, segundo Hoe ${ }^{(\mathbf{1 4 , 2 5 )}}$. Sham e Choy encontraram $85 \%$ de comprometimento desta região ${ }^{(\mathbf{2 6})}$. A partir do espaço parafaríngeo, o tumor pode estender-se superiormente, anteriormente, lateralmente ou posteriormente.

A extensão superior do carcinoma da nasofaringe é a mais freqüente rota de disseminação direta $(48 \%)^{(\mathbf{1 9 , 2 5})}$. A extensão intracraniana pode ocorrer por destruição direta da base do crânio ou por extensão para o seio cavernoso através do forame lacerado ou do forame oval. A extensão superior do tumor é visualizada como infiltração do seio esfenoidal com opacificação ou presença de líquido e destruição óssea. As áreas mais comuns de destruição óssea na base do crânio são o clivo, o forame lacerado e a fossa craniana média, ao redor do soalho do seio esfenóide e forame jugular (Figura 6).

A disseminação do tumor pelo forame lacerado é perivascular através da artéria carótida e resulta em erosão do canal carotídeo (Figura 7). A disseminação através do forame oval é perineural, resultando em erosão na base do esfenóide. Uma via de disseminação menos comum para a fossa craniana média é a perineural através do forame redondo ${ }^{(14,27)}$. É importante lembrar que a invasão da base do crânio independe 


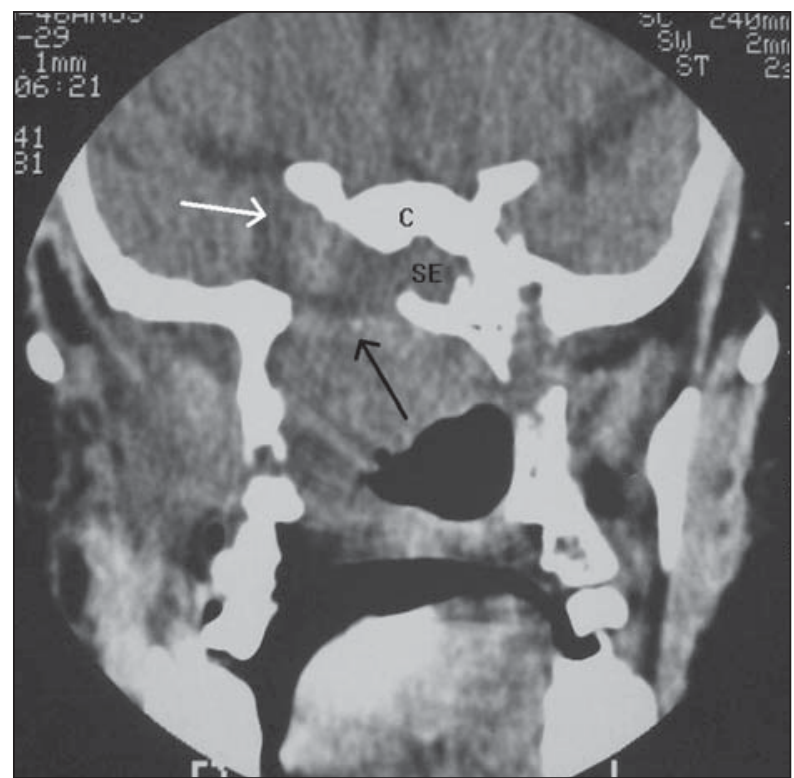

Figura 6. TC coronal pré-contraste evidenciando extensa lesão com densidade de partes moles da nasofaringe à direita, que invade a base do crânio através do esfenóide (seta preta), erodindo o clivo (C) e acometendo o seio cavernoso ipsilateral (seta branca).

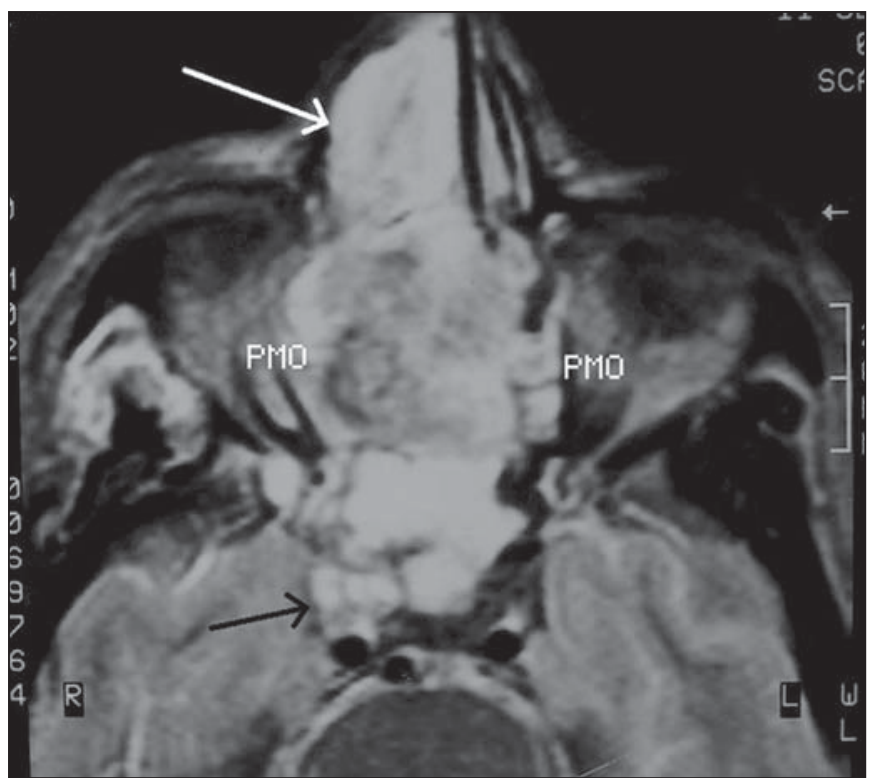

Figura 7. RM axial T2 (TR 2.500/TE 80) mostrando extensa lesão heterogênea, de aspecto expansivo, predominantemente hiperintensa, abaulando as paredes mediais das órbitas bilateralmente (PMO), estendendo-se anteriormente para a fossa nasal (seta branca) e superiormente atingindo o seio cavernoso à direita (seta preta). Notar o contato da lesão com a carótida interna à direita. do tamanho do tumor, variando desde discreta erosão até franca destruição óssea. Outros achados concomitantes na invasão intracraniana são o comprometimento predominantemente das cisternas da base, dos seios cavernosos, associada a paralisia dos pares cranianos acometidos ${ }^{(2,17)}$

Low et al. relataram o acometimento do ângulo cerebelopontino por esses carcinomas, ressaltando a dificuldade diagnóstica e terapêutica desta entidade, já que os pacientes estudados apresentavam doença avançada ou recorrência tumoral de uma doença avançada previamente tratada ${ }^{(28)}$.

Deve-se suspeitar de recorrência da doença se o paciente apresentar sintomas neurológicos sem explicação aparente, como perda auditiva neurossensorial, zumbido ou paralisia facial ${ }^{(28)}$.

A extensão posterior é a segunda rota mais freqüente de disseminação direta $(40 \%)^{(\mathbf{1 4})}$. Quando o tumor se estende para o espaço retrofaríngeo é observada massa anterior aos músculos pré-vertebrais. Nesta localização há linfonodos retrofaríngeos e pode ser difícil distinguir o envolvimento linfonodal da extensão direta pelo tumor. A infiltração do espaço pré-vertebral é identificada como massa posterior aos músculos pré-vertebrais e acontece em 14\% dos casos (Figura 8).
Na extensão ântero-lateral pode ocorrer invasão do espaço mastigador, incluindo a fossa infratemporal (14\%).

Inferiormente, os carcinomas invadem a orofaringe através das paredes laterais da faringe, pelos pilares anterior e posterior das tonsilas palatinas. Como este tipo de disseminação geralmente é submucoso, pode apresentar-se clinicamente oculta.
A forma de disseminação submucosa pode estar clinicamente oculta e a TC e a RM podem ser úteis na detecção deste tipo de disseminação ou para identificar áreas suspeitas, indicando a biópsia da região.

Como já foi dito, esses tumores podem ser pequenos e infiltrativos causando ou não efeito de massa; nesses casos, a obliteração dos planos gordurosos e a perda da

Figura 8. RM sagital T1 (TR 520/TE 20) mostrando extensa lesão heterogênea acometendo a parede póstero-superior da nasofaringe, detendo-se no clivo (seta preta) e anteriormente invadindo a fossa nasal (seta branca).

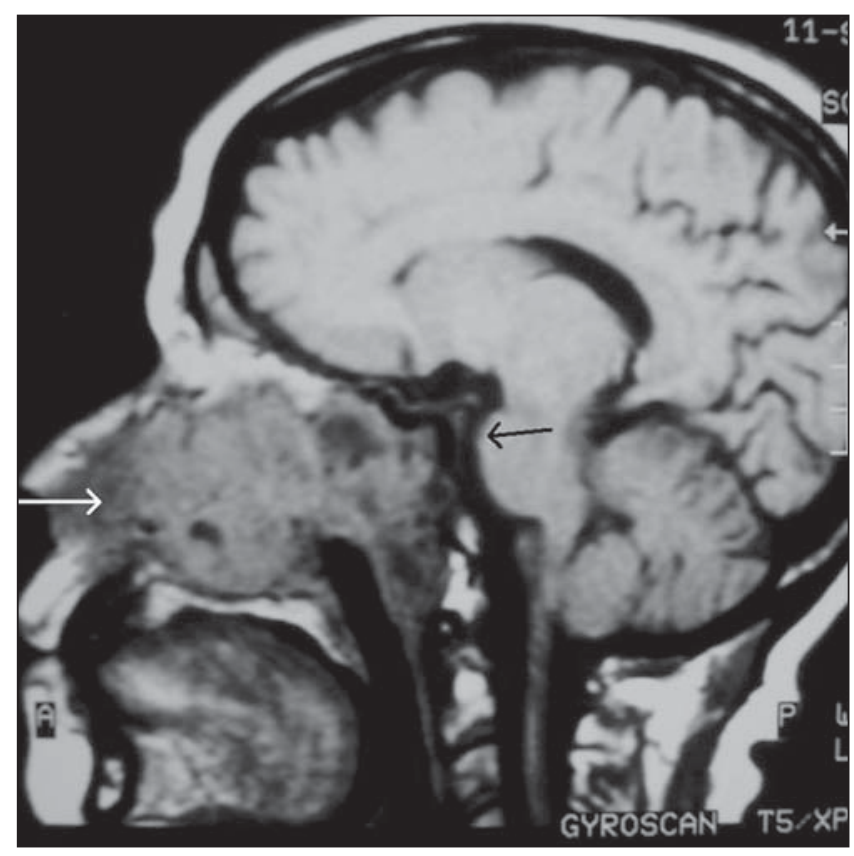


definição das margens musculares são achados diagnósticos de grande valia, e a RM com uso do meio de contraste (gadolínio) mais a supressão de gordura tem-se mostrado superior à TC na avaliação das partes moles, tanto da região profunda como da superficial da nasofaringe, além de poder diferenciar claramente tecido linfóide da musculatura ${ }^{(17,19)}$. Este fato é muito importante, já que o fator prognóstico mais relevante no carcinoma da nasofaringe está na profundidade e no grau de infiltração de estruturas vizinhas e não no seu tamanho ${ }^{(29)}$. Entretanto, a TC é melhor para demonstrar a envolvimentos sutis das estruturas ósseas da base do crânio ${ }^{(6,30)}$.

Ambos os métodos têm papel essencial e complementar no estadiamento e no tratamento dos pacientes portadores de cânceres da nasofaringe. Já a tomografia por emissão de pósitrons (positron emission tomographic scanning) acessa de maneira mais adequada tumores recorrentes e metástases linfonodais muito pequenas ${ }^{(2,17)}$.

Como não é possível, pelos exames de imagem, suspeitar do tipo histológico da lesão, fato importante, já que o prognóstico é diferente para os diferentes tipos celulares, resta ao radiologista mapear de forma precisa os sítios invadidos e auxiliar o clínico/cirurgião no correto estadiamento (Tabela 1) (Figura 9).

Tipicamente, os carcinomas de células escamosas são massas com coeficiente de atenuação similar ao dos músculos e não mostram realce significativo após administração endovenosa do material de contraste na TC. Na RM esses tumores apresentam intensidade de sinal intermediária em todas as sequiências. As interfaces tumor/tecidos moles são demonstradas de maneira mais adequada pela RM, enquanto a destruição óssea discreta é mais bem evidenciada pela TC. A extensão neoplásica através dos forames lacerado e oval é mais bem apreciada por meio da RM. A utilização do contraste paramagnético por via endovenosa (gadolínio) é vantajosa no estudo por RM, já que o intenso realce tumoral permite melhor delimitação da lesão, evitando, dessa forma, que se superestimem suas dimensões, fenômeno que é habitual nas margens sem contraste, em função da presença de edema e processo inflamatório perilesional ${ }^{(31,32)}$ (Figuras 10A e 10B).

Tabela 1 Estadiamento TNM dos tumores epiteliais da nasofaringe.

Tumor primário*
T1 - tumor confinado à nasofaringe
T2 - tumor estendendo-se para os tecidos da orofaringe e/ou fossa nasal
T2a - sem extensão para o espaço parafaríngeo
T2b - com extensão para o espaço parafaríngeo
T3 - tumor que destrói as estruturas ósseas e/ou invade os seios paranasais
T4 - tumor que apresenta extensão intracraniana e/ou compromete nervos cranianos, fossa
infratemporal, hipofaringe ou órbita
Linfonodos
Nx - linfonodos regionais não são clinicamente acessados
NO - não há linfonodos clinicamente positivos
N1 - linfonodo homolateral único, positivo, menor de 6 cm no maior diâmetro, acima da fossa
clavicular ${ }^{\dagger}$
N2 - linfonodos bilaterais, positivos, menores de 6 cm no maior diâmetro, acima da fossa clavicular
N3 - metástases linfonodais
$\quad$ N3a - maior que 6 cm no maior diâmetro
$\quad$ N3b - extensão linfonodal para a fossa supraclavicular
Metástases
M0 - não há evidências de metástases
M1 - metástases distantes presentes

* Reproduzido de: Mukerii SK. Pharynx. In: Som PM, Curtin HD, editors. Head and neck imaging. 4th ed. St. Louis: Mosby, 2003;1478.

${ }^{\dagger}$ A fossa supraclavicular é delimitada pelo triângulo de Ho, um plano definido pelas margens superior do esterno, laterais da clavícula e o ponto posterior onde o pescoço se encontra com o ombro.

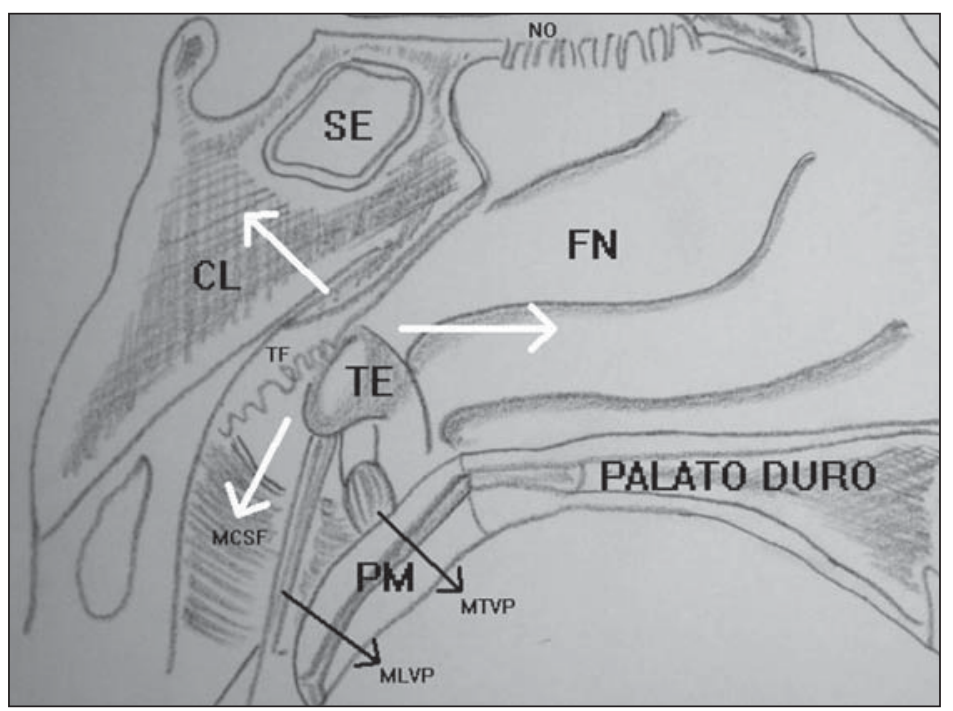

Figura 9. Desenho esquemático, visão sagital. NO, nervo olfatório; SE, seio esfenoidal; FN, fossa nasal; CL, clivo; TF, tonsila faríngea (adenóide); TE, tuba auditiva (tuba de Eustáquio); MTVP, músculo tensor do véu palatino; MLVP, músculo levantador do véu palatino; PM, palato mole. Setas brancas: potenciais subsítios de disseminação dos carcinomas da nasofaringe.

Para um estadiamento completo devese estudar também o acometimento linfonodal, presente em aproximadamente $90 \%$ dos pacientes no momento do diagnóstico. Os linfonodos retrofaríngeos são, usualmente, os primeiros a serem acometidos, mas podem apresentar-se normais caso estejam obliterados por processos inflamató- rios prévios. Os seguintes são os dos níveis II e III, e ocasionalmente os dos níveis I e V podem estar comprometidos ${ }^{(2)}$ (Tabela 2).

O tratamento de escolha para os carcinomas da nasofaringe geralmente é a radioterapia, por isso os métodos de imagem são tão importantes no mapeamento tumoral para o planejamento radioterápico ${ }^{(33)}$. 

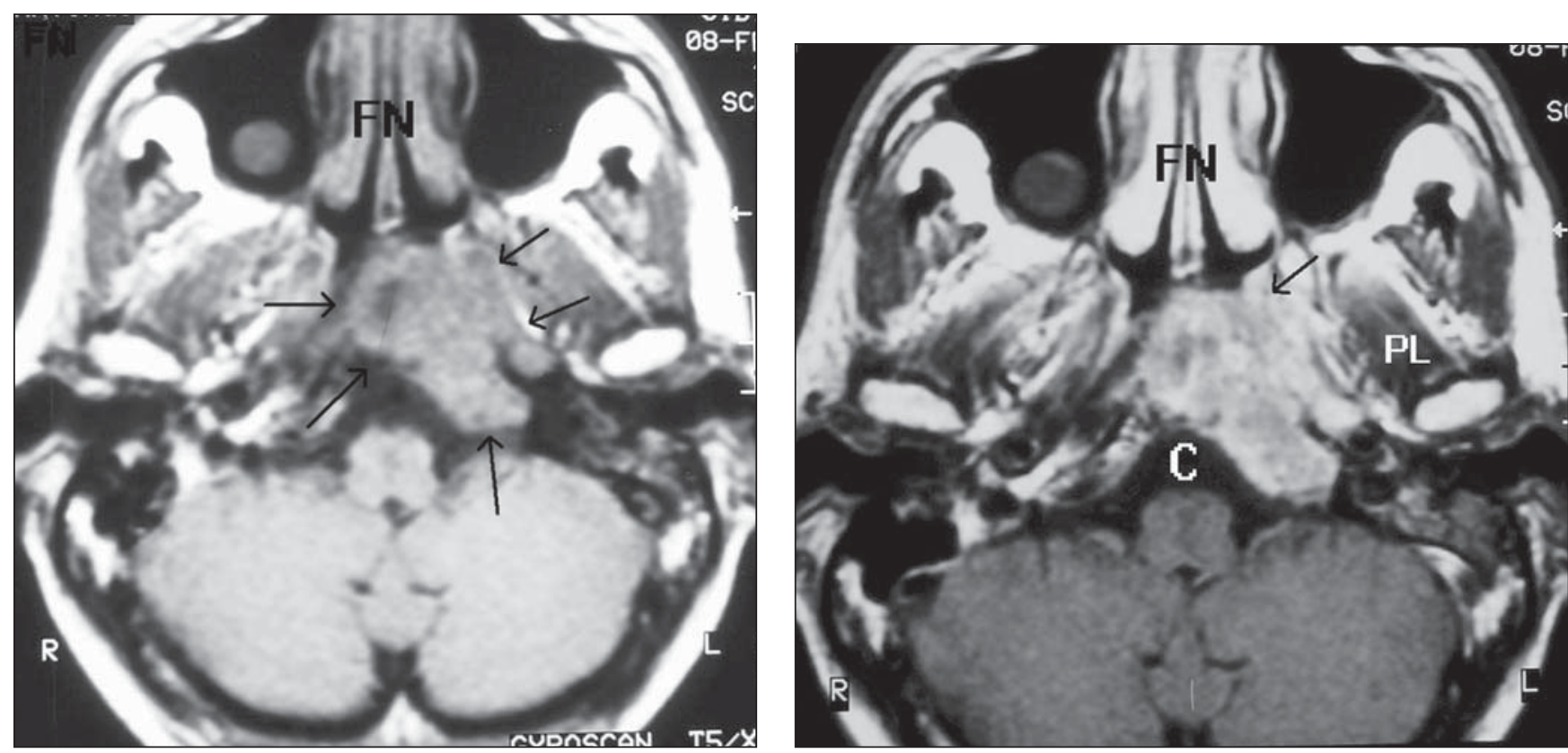

A

B

Figura 10(A,B). A: RM axial T1 (TR 520/TE 20) mostrando lesão de intensidade intermediária acometendo a parede póstero-lateral esquerda da nasofaringe (setas), obliterando a quase totalidade da sua luz, tendo como limite anterior a fossa nasal (FN) sem invadi-la. B: Após administração de gadolínio nota-se que a lesão apresenta intenso realce heterogêneo e delimitando de maneira mais adequada a lesão que acomete a lâmina pterigóidea medial, a fossa pterigóidea (seta preta), o músculo pterigóideo medial, a tuba auditiva, o toro tubário, o recesso faríngeo e o tecido adenoidiano (posteriormente), detendo-se no clivo (CL). (FN, fossa nasal; PL, músculo pterigóideo lateral).

Tabela 2 Classificação linfonodal dos carcinomas da nasofaringe segundo a American Joint Committee on Cancer*.

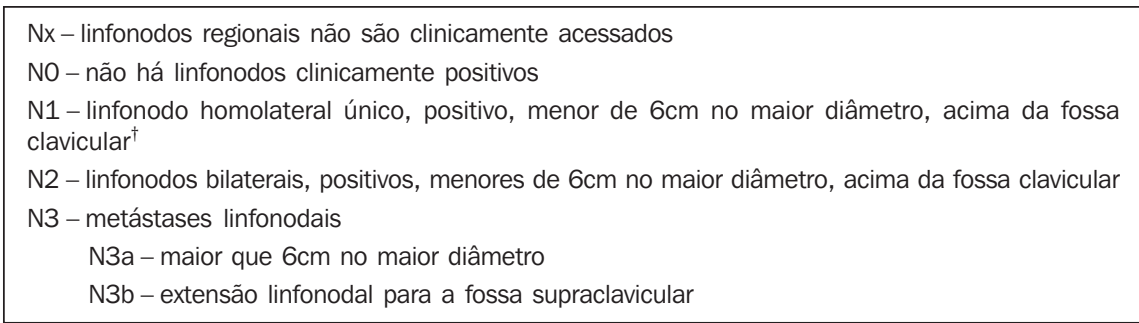

* Reproduzido de: Som PM, Brandwein MS. Lymph nodes. In: Som PM, Curtin HD, editors. Head and neck imaging. 4th ed. St. Louis: Mosby, 2003;1882.

${ }^{\dagger}$ A fossa supraclavicular é delimitada pelo triângulo de Ho, um plano definido pelas margens superior do esterno, laterais da clavícula e o ponto posterior onde o pescoço se encontra com o ombro.

Todavia, a avaliação pós-tratamento, tanto pela TC quanto pela RM, apresenta baixas sensibilidade $(45 \%$ a $67 \%$ para a TC e $56 \%$ para a RM) e especificidade (64\% a $70 \%$ para a TC e $78 \%$ a $83 \%$ para a $\mathrm{RM})^{(\mathbf{3 4})}$.

\section{REFERENNCIAS}

1. Parker GD, Harnsberger HR, Jacobs JM. The pharyngeal mucosal space. Semin Ultrasound CT MR 1990;11:460-475.

2. Mukerji SK. Pharynx. In: Som PM, Curtin HD, editors. Head and neck imaging. 4th ed. St. Louis Mosby, 2003;1470-1484.

3. Silver AJ, Mawad ME, Hilal SK, Sane P, Ganti SR. Computed tomography of the nasopharynx and related spaces. Part II: Pathology. Radiology 1983;147:733-738.

4. Last RJ. Anatomy regional and applied. 6th ed. London: Churchill Livingstone, 1978.

5. Testut L, Latarjet A. Aparato de la digestión. In: Testut L, Latarjet A. Tratado de anatomía humana $8^{\mathrm{a}}$ ed. Barcelona-Buenos Aires: Salvat Editores, 1944;112-133.

6. Braun IF. MRI of the nasopharynx. Radiol Clin North Am 1989;27:315-330.

7. Mancuso AA, Bohman L, Hanafee W, Maxwell D. Computed tomography of the nasopharynx: normal and variants of normal. Radiology 1980; 137(1 Pt 1):113-121.

8. Khoo FY, Kanagasuntheram R, Chia KB. Variations of the lateral recesses of the nasopharynx. Arch Otolaryngol 1967;86:456-462.
9. Cormack DH. Ham's Histology. 9th ed. Philadelphia: JB Lippincott, 1987.

10. Harnsberger HR. Handbooks in radiology: head and neck imaging. Chicago: Mosby-Year Book, 1990.

11. Muraki AS, Mancuso AA, Harnsberger HR, Johnson LP, Meads GB. CT of the oropharynx, tongue base, and floor of the mouth: normal anatomy and range of variations, and applications in staging carcinoma. Radiology 1983;148:725-731.

12. Olsen WL, Jeffrey RB Jr, Sooy CD, Lynch MA, Dillon WP. Lesions of the head and neck in patients with AIDS: CT and MR findings. AJR Am J Roentgenol 1988;151:785-790.

13. Lingermar RE, Shellhamer RH. Benign neoplasms of the nasopharynx. In: Cummings $\mathrm{CW}$ Fredrickson JM, Harker LA, et al, editors. Otolaryngology - head and neck surgery. St. Louis: Mosby, 1986;1269.

14. Fu KK. Treatment of tumor of nasopharynx. In Thauley SE, Ponje WR, Batsakis JG, Lindeberg $\mathrm{RD}$, editors. Comprehensive management of head and neck tumors. Philadelphia: WB Saunders, 1987;30:649-683.

15. Nicholls JM, Agathanggelou A, Fung K, Zeng X, Niedobitek G. The association of squamous cell carcinomas of the nasopharynx with Epstein-Barr virus shows geographical variation reminiscent of Burkitt's lymphoma. J Pathol 1997;183:164-168.

16. Zhang XS, Wang HH, Hu LF, et al. V-val subtype of Epstein-Barr virus nuclear antigen 1 preferentially exists in biopsies of nasopharyngeal carcinoma. Cancer Lett 2004;211:11-18.

17. Weber AL, al-Arayedh S, Rashid A. Nasopharynx: clinical, pathologic, and radiologic assessment. Neuroimaging Clin N Am 2003;13:465-483. 
18. Macdonald MR, Freeman JL, Hui MF, et al. Role of Epstein-Barr virus in fine-needle aspirates of metastatic neck nodes in the diagnosis of nasopharyngeal carcinoma. Head Neck 1995; 17 : 487-493.

19. Hoe JWM. Computed tomography of nasopharyngeal carcinoma. A review of CT appearances in 56 patients. Eur J Radiol 1989;9:83-90.

20. Su CY, Hsu SP, Lui CC. Computed tomography, magnetic resonance imaging and electromyographic studies of tensor veli palatini muscles in patients with nasopharyngeal carcinoma. Laryngoscope 1993;103:673-678.

21. Low WK, Goh YH. Uncommon otological manifestations of nasopharyngeal carcinoma. J Laryngol Otol 1999;113:558-560.

22. Miura T, Hirabuki N, Nishiyama K, et al. Computed tomographic findings of nasopharyngeal carcinoma with skull base and intracranial involvement. Cancer 1990;65:29-37.

23. Hoover LA, Hanafee WN. Differential diagnosis of nasopharyngeal tumors by computed tomography scanning. Arch Otolaryngol 1983;109:43-47.

24. Pandolfo I, Bandino A, Longo M, Faranda C. Perineural spread of nasopharyngeal carcinoma: radiological and CT demonstration. Eur J Radiol 1988;8:231-235.

25. Hoe J. CT of nasopharyngeal carcinoma: significance of widening of the preoccipital soft tissue on axial scans. AJR Am J Roentgenol 1989;153: 867-872.

26. Sham JST, Choy D. Prognostic value of paranasopharyngeal extension of nasopharyngeal carcinoma on local control and short-term survival. Head Neck 1991;13:298-310.

27. Teresi LM, Lufkin RB, Vinuela F, et al. MR imaging of the nasopharynx and floor of the middle cranial fossa. Part II. Malignant tumors. Radiology 1987;164:817-821

28. Low WK, Fong KW, Chong VF. Cerebellopontine angle involvement by nasopharyngeal carcinoma. Am J Otol 2000;21:871-876.
29. Sakata K, Hareyama M, Tamakawa M, et al. Prognostic factors of nasopharynx tumors investigated by MR imaging and the value of MR imaging in the newly published TNM staging. Int J Radiat Oncol Biol Phys 1999;43:273-278.

30. Dillion WP, Mills CM, Kjos B, DeGroot J, BrantZawadzki M. Magnetic resonance imaging of the nasopharynx. Radiology 1984;152:731-738.

31. Souza RP, Rapoport A. O valor da tomografia computadorizada e da ressonância magnética na avaliação do espaço parafaríngeo. Parte II: tumores e pseudotumores. Rev Imagem 1994;16:7-24.

32. Phillips CD, Gay SB, Newton RL, Levine PA Gadolinium-enhanced MRI of tumors of the head and neck. Head Neck 1990;12:308-315.

33. Chong VF, Fan YF, Mukherji SK. Carcinoma of the nasopharynx. Semin Ultrasound CT MR 1998;19:449-462.

34. Chong VF, Fan YF. Detection of recurrent nasopharyngeal carcinoma: MR imaging versus CT Radiology 1997;202:463-470. 